\title{
Linkage between copepods and bacteria in the North Atlantic Ocean
}

\author{
Daniele De Corte $^{1, *, * *}$, Itziar Lekunberri ${ }^{1, * *}$, Eva Sintes $^{1}$, Juan Antonio L. Garcia ${ }^{1}$, \\ Santiago Gonzales ${ }^{2}$, Gerhard J. Herndl ${ }^{1,2}$
} ${ }^{1}$ Department of Limnology and Oceanography, Center of Ecology, University of Vienna, Althanstrasse 14, 1090 Vienna,
Austria

${ }^{2}$ Department of Biological Oceanography, Royal Netherlands Institute for Sea Research (NIOZ), PO Box 59, 1790 AB, Den Burg, The Netherlands

\begin{abstract}
Copepods and bacteria are fundamental components of the pelagic food web and play a major role in biogeochemical cycles. Marine bacteria have a free-living or particleattached lifestyle, but as members of the microbial food web, the only biotic interaction of bacteria is commonly assumed to be with their predators (protists and/or viruses). However, a copepod's body is highly enriched in organic matter and harbors a large and complex bacterial community. The aim of this study was to compare the composition of the free-living bacterial community of the open Atlantic to that associated with copepods. We used 454 highthroughput sequencing of the 16S rRNA gene to decipher the bacterial community composition associated with this zooplankton group and the ambient water. Significant differences were found between the bacterial communities associated with the dominant copepod families (Calanoida: Centropagidae and Clausocalanidae; Cyclopoida: Corycaeidae, Oncaeidae, and Lubbockiidae) and the ambient water. Bacilli and Actinobacteria dominated the copepodassociated community and Alphaproteobacteria, Deltaproteobacteria, and Synechococcus dominated the free-living community. However, the presence of shared bacterial operational taxonomic units (OTUs) between these 2 distinct habitats suggests a dynamic exchange of bacteria between seawater and copepods. Taken together, our results support the hypothesis that the interior and exterior surfaces of copepods provide a specific niche with a strong selective pressure for bacteria.
\end{abstract}

KEY WORDS: Microbes $\cdot$ Zooplankton $\cdot$ Open ocean $\cdot 454$ pyrosequencing

\section{INTRODUCTION}

Prokaryotes constitute the largest fraction of living biomass in marine ecosystems and are the main force driving biogeochemical cycles (Azam et al. 1983). In the oceanic water column, the majority of the prokaryotes are free-living, with commonly less than $5 \%$ of total prokaryotic cells associated with aggregates (Bell \& Albright 1982, Unanue et al. 1992). However, several studies have reported bacterial abundances associated with various microhabitats such as particles, aggregates, fecal pellets, and zooplankton exceeding those of freeliving bacteria (Simon et al. 2002, Tang et al. 2010). Also, attached bacteria commonly exhibit high growth rates and enzymatic activities (Karner \& Herndl 1992, Grossart et al. 2006). The microhabitats of these attached bacteria are frequently characterized by concentrations of organic matter and inorganic nutrients that are orders of magni- 
tude higher than in the surrounding water (Bochdansky \& Herndl 1992, Alldredge 2000, Grossart \& Tang 2010, Tang et al. 2010). These distinctly different microhabitats may favor biogeochemical reactions that otherwise would not occur in the oceanic water column (Grossart \& Tang 2010). The anoxic and hypoxic conditions found in some pelagic aggregates, animal guts, and fecal pellets favor anaerobic reactions not occurring in the surrounding oxygenated water (Alldredge \& Cohen 1987, Deangelis \& Lee 1994, Grossart \& Tang 2010, Tang et al. 2011). Furthermore, several studies have shown that the interactions between prokaryotes and predators such as protists and viruses are substantially different in these microhabitats as compared to the ambient seawater (Caron 1987, Riemann \& Grossart 2008, Grossart \& Tang 2010).

Marine copepods provide a complex microhabitat in marine ecosystems, with their complex body structure and extensive surface potentially available for microbial colonization (Tang et al. 2010). Furthermore, copepods contribute to the microbial food web through the release of biologically available dissolved organic matter and nutrients during the digestive processes (Azam et al. 1983, Møller et al. 2003, Tang 2005, Møller 2007, Tang et al. 2010). In contrast to detrital particles, copepods can collect organic compounds and cells through the ingestion of food, thereby allowing a continuous production and release of prokaryotes through their fecal pellets (Tang 2005). Moreover, many zooplankton species perform vertical migration (Kobari \& Ikeda 2001). This migration in stratified waters favors the dispersal and acquisition of microbes from different water layers and allows them to cross physical barriers, such as pycnoclines (Grossart et al. 2010). Several abundant open-ocean copepods exhibit diel vertical migration potentially favoring dispersal of copepod-associated bacteria over the euphotic to mid-mesopelagic layers (Steinberg et al. 2000, Grossart et al. 2010, Tang et al. 2010).

The aim of this study was to compare the phylogenetic composition of the bacterial community associated with copepods collected in the North Atlantic Ocean to that of the ambient water using 454 pyrosequencing. Specifically, we hypothesized that a variable transient bacterial community is present in the copepods in addition to a stable resident community. The transient community reflects the composition of the ambient water, while the resident community is specifically adapted to the microenvironmental conditions in the copepods.

\section{MATERIALS AND METHODS}

\section{Sampling of ambient water}

Water samples were collected during the MEDEAI cruise (October 2011) on board RV 'Pelagia' at 4 stations along a latitudinal transect in the North Atlantic from $24^{\circ} 40^{\prime} \mathrm{N}, 34^{\circ} 56^{\prime} \mathrm{W}$ to $30^{\circ} 27^{\prime} \mathrm{N}, 24^{\circ} 32^{\prime} \mathrm{W}$ (See Fig. S1 in the Supplement at www.int-res.com/ articles/suppl/a072p215_supp.pdf).

Seawater samples were collected with a Seabird conductivity-temperature-depth (CTD) rosette sampler equipped with 18 Niskin bottles (25 l each). To determine the bacterial community composition of the ambient seawater, $10 \mathrm{l}$ of water were sampled from the lower euphotic zone (about $100 \mathrm{~m}$ depth) and from $\sim 750 \mathrm{~m}$ depth.

The seawater was filtered through a $0.2 \mu \mathrm{m}$ GTTP membrane filter (Millipore) and subsequently, the filters were stored at $-80^{\circ} \mathrm{C}$ until further processing in the laboratory. Although these samples include some particle-attached bacteria, the free-living community is dominant (Bochdansky et al. 2010). Thus, we refer to the ambient seawater bacterial community as the free-living community.

\section{Sampling of zooplankton}

Zooplankton were collected at the same stations as the ambient water using vertical plankton tows ( $200 \mu \mathrm{m}$ mesh size, hoisted at $30 \mathrm{~m} \mathrm{~min}^{-1}$ ) from $750 \mathrm{~m}$ to the surface. Water samples were collected at the 2 depth layers $(\sim 100, \sim 750 \mathrm{~m})$ within which the copepods migrate during the diel cycles (Steinberg et al. 2000, Tang et al. 2010), to compare the composition of the free-living bacterial community with the zooplankton-associated bacterial community obtained from the integrated net tows.

The content of the cod end of the plankton net was transferred into a plankton splitter and then concentrated over a $70 \mu \mathrm{m}$ mesh Nitex screen. The zooplankton samples were then transferred into $2 \mathrm{ml}$ Eppendorf tubes and stored at $-80^{\circ} \mathrm{C}$ until sorting. In the laboratory, the zooplankton were thawed to room temperature, transferred to a Petri dish filled with $0.2 \mu \mathrm{m}$ filtered seawater for sorting of the dominant copepod taxa (Calanoida: Centropagidae and Clausocalanidae; Cyclopoida: Corycaeidae, Oncaeidae, and Lubbockiidae). To evaluate the gut-associated bacteria of different copepods, 10 individuals of each taxon were collected and washed 3 times with Milli$\mathrm{Q}$ water to remove bacterial cells associated with the 
external surface of the copepods. Subsequently, the copepods were transferred into sterile Eppendorf tubes for nucleic acid extraction.

\section{DNA extraction}

The DNA of the ambient-water samples was extracted using an Ultraclean Soil DNA isolation Kit (MoBIO Laboratories). The DNA from the copepod samples was extracted using a phenol-chloroform extraction protocol (Weinbauer et al. 2002), preceded by a bead-beating step to facilitate lysis of the copepods. To check the quality of the DNA following extraction, a NanoDrop ND-1000 spectrophotometer (NanoDrop Technologies) was used.

\section{Pyrosequencing of the 16S rDNA bacterial community}

The 16S rRNA genes (16S rDNA) of the zooplankton and ambient-water samples were PCR amplified with the bacterial primers 341f (5'-CCT ACG GGA GGC AGC AG-3') and 907r (5'-CCG TCA ATT CMT TTG AGT TT-3') (Muyzer et al. 1998, Grossart et al. 2009). The PCR amplification of the 16S rRNA gene of the samples was carried out in a $50 \mu \mathrm{l}$ reaction volume using Fermentas Taq polymerase (Thermo Scientific) in a Mastercycler (Eppendorf) with the following parameters: initial denaturation at $94^{\circ} \mathrm{C}$ for $3 \mathrm{~min}$, followed by 30 cycles of denaturation at $94^{\circ} \mathrm{C}$ for $1 \mathrm{~min}$, annealing at $55^{\circ} \mathrm{C}$ for $1 \mathrm{~min}$, and extension at $72^{\circ} \mathrm{C}$ for $1 \mathrm{~min}$, with a final extension at $72^{\circ} \mathrm{C}$ for $7 \mathrm{~min}$. The PCR products were additionally purified with a PCR purification kit (5-Prime). The quality of the PCR product was checked on $2 \%$ agarose gel. The $16 \mathrm{~S}$ rDNA amplicons were subsequently sequenced in a Roche 454 GS Junior next generation sequencing platform based on the Titanium chemistry by IMGM Laboratories GmbH (Martinsried, Germany). All samples were barcoded using multiplex identifiers and sequenced together in 1 run. The resulting sequences were divided into 4 groups: 2 orders of copepods (Calanoida and Cyclopoida) and 2 water layers (Deep, corresponding to $\sim 750 \mathrm{~m}$; and Surface, corresponding to $100 \mathrm{~m}$; see Table $\mathrm{S} 1$ in the Supplement).

\section{Bioinformatic analysis and phylogenetic classification}

The bioinformatic analysis of the 16S rDNA sequences largely followed the standard operating pro- cedure pipeline of Mothur software, version 1.31 (Schloss 2009). The 16S rDNA pyrotags were sorted according to their respective barcode into the different samples. The raw sequence reads were filtered, trimmed, and quality checked, and sequences smaller than $200 \mathrm{bp}$ were discarded. Subsequently, the sequences were aligned with the SILVA database, and the pairwise distance matrix was calculated. The 16S rDNA sequences with a $97 \%$ sequence similarity were clustered into operational taxonomic units (OTUs). Taxonomic assignment was performed using QIIME (Caporaso et al. 2010), and all unclassified bacteria at the phylum level were discarded. Additionally, MEGAN (Huson et al. 2007) was used to build the hierarchical phylogenetic tree of the bacterial community as an alternative to QIIME for taxonomic identification. The MEGAN analysis was based on BLAST results (Altschul et al. 1997) against SILVA and Greengenes databases (data not shown) following the NCBI taxonomy (Sayers et al. 2012). Rarefaction curves, Chao1, ACE richness, and the Shannon index of diversity were calculated with Mothur (Schloss 2009).

Pairwise UniFrac distance and principal coordinate analysis (PCoA) (Lozupone \& Knight 2005) were used to compare the bacterial community composition in the different samples (implemented in QIIME). The established phylogenetic tree was built with Mothur (Schloss 2009), and the Unifrac distance matrix was calculated with FastUnifrac (Lozupone \& Knight 2005). The Unifrac distance matrix was calculated unweighted using only presence-absence information of bacterial OTUs, or weighted and thus taking the relative proportion of each bacterial OTU to the total bacterial community into account. A $t$-test (implemented in Sigma Plot v.11) was used to test for the statistical difference between samples.

\section{RESULTS}

\section{Analysis of the pyrosequencing library}

The 454 pyrosequencing analysis was performed to investigate the differences between the bacterial community composition associated with 2 orders of copepods (Cyclopoida and Calanoida) and the bacterioplankton community collected from the 2 boundary depth layers ( 750 and $100 \mathrm{~m}$ depths) at the same location as the copepods were collected. In total, we obtained 65855 reads for the entire set of samples with an average length of $450 \mathrm{bp}$. The trimming of low-quality reads resulted in 25101 sequences with 
an average length of $307 \mathrm{bp}$ used for further analyses (Table S1 in the Supplement). From the total number of trimmed sequences, 3970 and 12978 reads were categorized as unique at the $97 \%$ and $100 \%$ similarity level, respectively.

\section{OTU richness in ambient water and copepods}

The rarefaction analysis showed different trends for the 2 sets of samples (Fig. 1). While the rarefaction curves for the copepod samples approached a plateau, the rarefaction curves of the ambient water samples did not level off (Fig. 1). Hence, the sequencing effort was sufficient to sample most members of the bacterial community associated with the copepods, while it was not sufficient for the ambient water samples. Moreover, these results indicate a lower diversity in the copepod-associated bacterial community as compared to the ambient-water community (Table 1). The Chao richness index estimated, on average, $231 \pm 57$ (average \pm SD) OTUs (ranging from 120$306, \mathrm{~N}=9$ ) for the copepod-associated bacterial communities and $1870 \pm 693$ OTUs (ranging from 7913026, $N=7$ ) for the ambient water (Table 1). Similar results were obtained with the ACE richness index (Table 1). Shannon and Simpson diversity indices

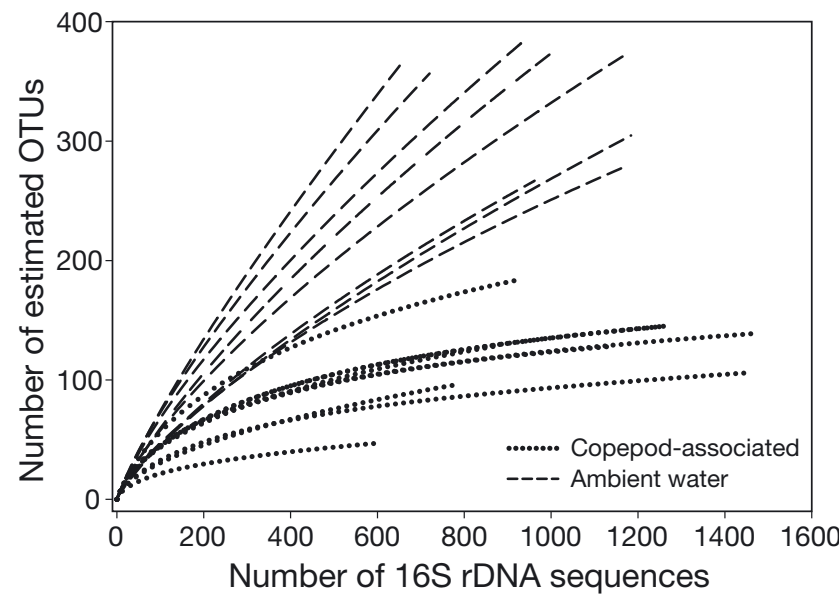

Fig. 1. Rarefaction curves obtained for the 16S rDNA sequences of calanoid and cyclopoid copepod-associated and ambient-water bacterial communities. Operational taxonomic units (OTUs) were defined at $97 \%$ sequence identity were computed for each sample using the $97 \%$ similarity threshold. These indices also indicated a higher diversity in the bacterial community of the ambient water as compared to the copepod-associated community (Table 1). Two of the 3 samples of the Cyclopoida-associated bacterial community collected at Stn 4 exhibited significantly lower ( $t$-test, $\mathrm{p}<0.01$ ) diversity than the other copepod samples. These 2 samples of Cyclopoida had the lowest number of OTUs ( $t$-test, $\mathrm{p}<0.01)$ and the lowest Shannon $(t$-test, $\mathrm{p}=0.01)$ and Simpson indices ( $t$-test, $\mathrm{p}<0.01)$ of the entire dataset (Table 1).

In the ambient water, the bacterial community at $100 \mathrm{~m}$ depth exhibited a lower diversity ( $t$-test, $\mathrm{p}=$ $0.02)$, a lower number of OTUs ( $t$-test, $p=0.02)$ and lower Shannon ( $t$-test, $\mathrm{p}<0.01)$ and Chao $(t$-test, $\mathrm{p}=$ 0.03 ) indices than that of the $750 \mathrm{~m}$ layer, although the ACE index was not significantly different between these depth layers ( $t$-test, $\mathrm{p}=0.86$; Table 1 ).

The most abundant bacterial OTU of the ambient water contributed on average $25 \%$ to the total number of ambient-water OTUs, while the most abundant copepod-associated bacterial OTU contributed only $18 \%$ to the total copepod-associated bacterial OTUs (see Fig. S2 in the Supplement). Singletons (OTUs appearing only once in the entire pyrosequencing library) accounted for $27 \%$ of the total number of bacterial OTUs of the ambient water, but only $8 \%$ of the copepod-associated OTUs (Fig. S2). 
The bacterial communities of the ambient water were dominated by a few very abundant OTUs and a large number of rare OTUs (Fig. S2). In contrast, members of the copepod-associated bacterial community were more evenly distributed than those of the ambient water with a comparatively low number of rare OTUs (Fig. S2).

\section{Composition of the bacterial community in the ambient water and in copepods}

The phylogenetic analysis of the 25101 sequences performed in QIIME using the Greengenes database revealed a clear clustering into 4 groups of bacterial communities (ambient water at $100 \mathrm{~m}$ and $750 \mathrm{~m}$ and calanoid and cyclopoid copepods; Table 2). Firmicutes contributed $23 \%$ and $27 \%$, Actinobacteria $22 \%$ and $19 \%$, and Alphaproteobacteria $20 \%$ and $11 \%$ to the Calanoida- and Cyclopoida-associated bacteria, respectively. Betaproteobacteria contributed 1.5\% and $16 \%$ to the Calanoida- and Cyclopoida-associated bacteria, respectively (Fig. 2a). This relatively high abundance of the Betaproteobacteria in cyclopoid copepods was mainly caused by 2 samples collected at Stn 4 where Betaproteobacteria contributed $53 \%$ to Cyclopoida-associated bacteria (Fig. 2a). Generally, the copepod-associated community was characterized by a relatively high contribution of chloroplasts, probably derived from ingested phytoplankton ( $7 \pm 8 \%$; Fig. 2a)

Although the composition of the bacterial community of the ambient water was rather uniform among the different stations, as was the composition of the copepod-associated bacterial community, 2 samples of Cyclopodia-associated bacterial communities were strikingly different from all other samples (Fig. 2a), specifically the bacteria associated with the families Oncaeidae and Lubbockiidae at Stn 4, although members of the Oncaeidae were also collected at other stations. These 2 samples were composed mainly of Betaproteobacteria (genus Burkholderiales, 51\%) and Flavobacteria (genus Flavobacteriales, $16 \%$; Fig. 2a,b).

The bacterioplankton community of the $100 \mathrm{~m}$ depth layer mainly consisted of Alphaproteobacteria (30\%), Cyanobacteria (32\%; mainly composed of Synechococcales, $31 \%$ ), and Actinobacteria (17\%). The bacterial community of the $750 \mathrm{~m}$ layer was mainly composed of members of Deltaproteobacteria (29\%), Alphaproteobacteria (20\%), Chloroflexi $(10 \%)$, SAR406 (10\%), and Gammaproteobacteria (6\%; Fig. 2a, Table 2).

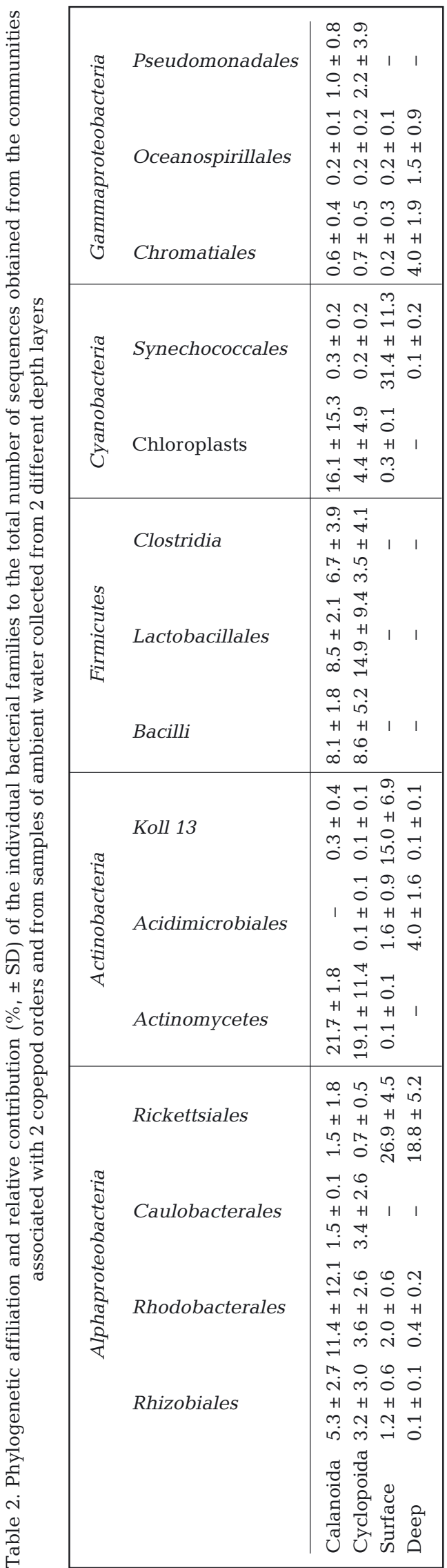



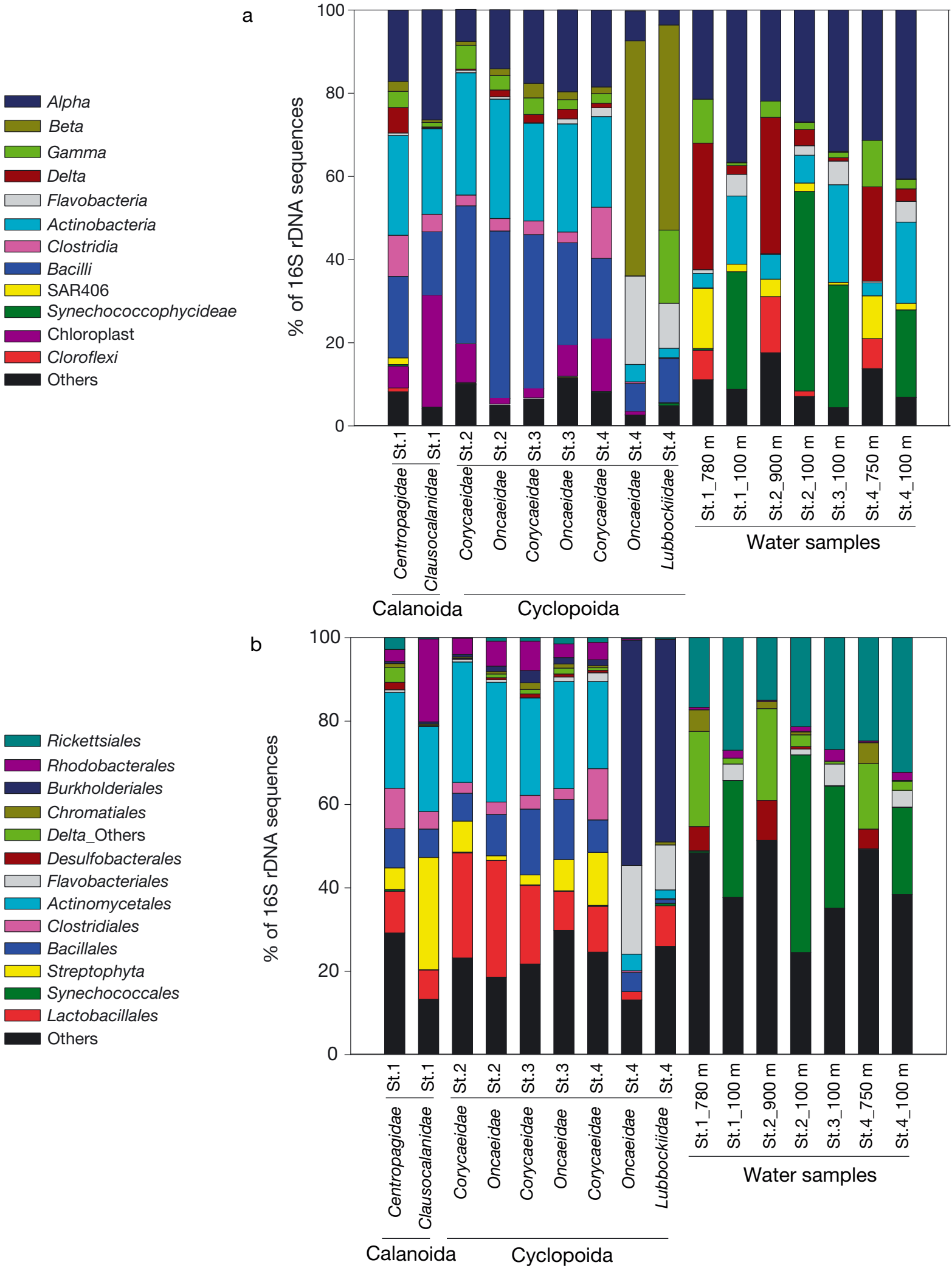

Fig. 2. Relative contribution of the more abundant phylogenetic (a) classes and (b) orders to the total number of 16S rDNA sequences obtained from copepod-associated and ambient-water bacterial communities 


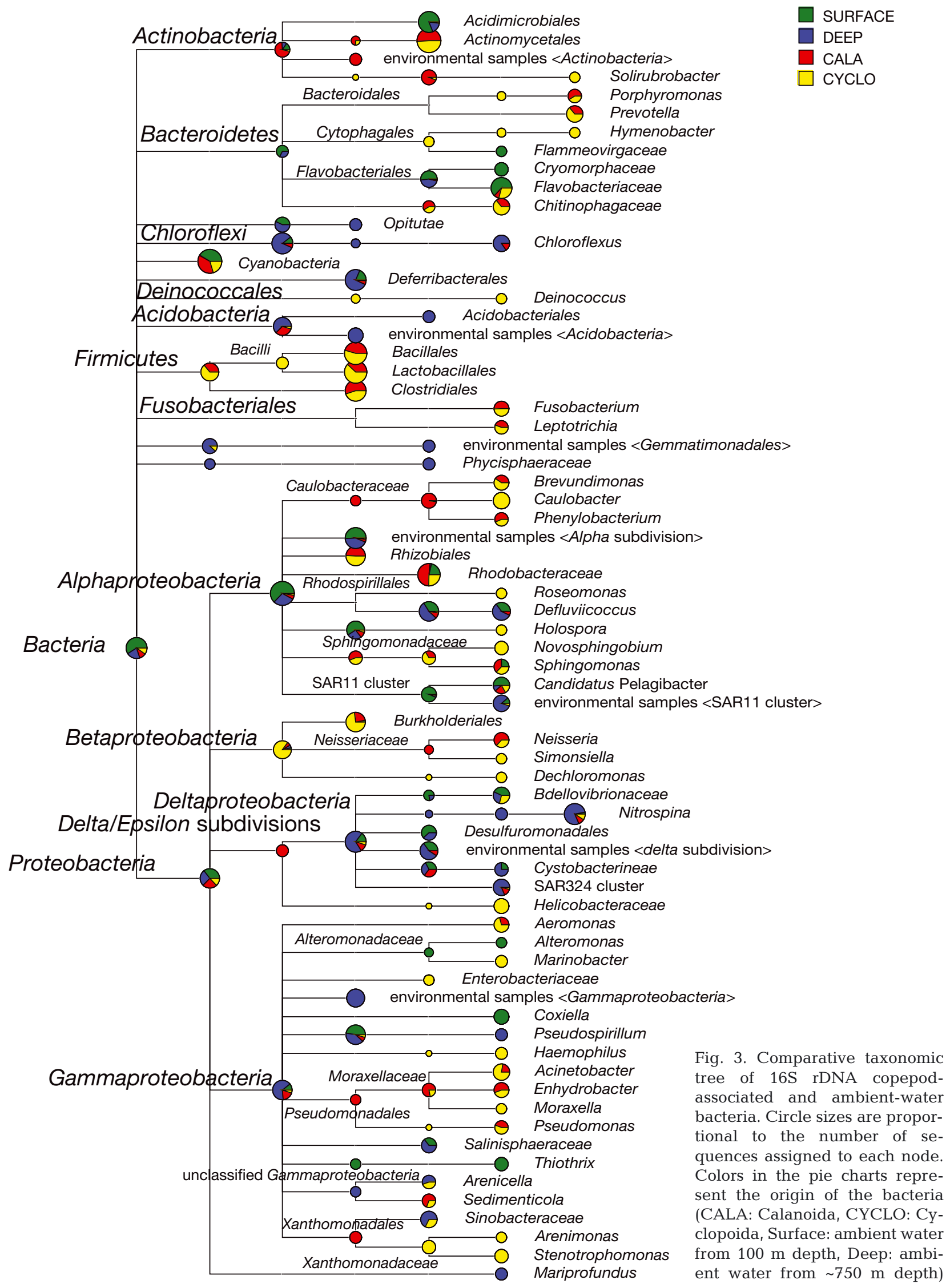


To investigate an alternative to the QIIME classifier and to directly visualize the distribution of individual bacterial taxa among the 2 copepod orders and the 2 depth layers, the samples were blasted against the SILVA and Greengenes database (data not shown). These results were visualized by MEGAN (Huson at al. 2007) using the BLAST hit-score to assign the taxonomy. As indicated in Fig. 3, some bacterial taxa associated with the 2 copepod orders were not present in the water column, including members of Firmicutes, Fusobacteriales, and most of the Betaproteobacteria. At the genus level, bacteria associated with copepods but absent in the ambient water belonged to the Actinomycetales, Bifidobacteriales, Bacteroidales, Deinicoccus, Bacillales, Lactobacillales, Clostridiales, Fusobacterium, Leptotrichia, Caulobacteraceae, Neisseriaceae, and Pseudomonadales (Fig. 3).

Conversely, a few taxa of the bacteria were specific to the ambient water. Ambient water-specific bacteria at the genus level belonged to the Acidimicrobiales, Flammeovirgaceae, Cryomorphaceae, Cystobacterineae, Alteromonas, Coxiella, Pseudospirillum, Thiothrix, and Mariprofundus (Fig. 3).

Most of the bacterial taxa were present in both the ambient water and associated with copepods; however, their contribution to the respective bacterial community differed among the 2 contrasting environments (Fig. 3). Although our data were analyzed with 2 different databases (SILVA and Greengenes), the phylogenetic affiliation of the bacterial 16S rRNA gene obtained with both databases was comparable. The results from the BLAST hit-score using the NCBI taxonomy of the 2 different databases (see Fig. S3 in the Supplement) were significantly correlated $(\mathrm{p}<$ $\left.0.01, r^{2}=0.94\right)$ with a slope close to unity. The only remarkable discrepancies between the 2 databases were detected for Actinomycetales and Rickettsiales, probably due to the lower number of sequences from these groups available in the SILVA database as compared to the Greengenes database (Fig. S3). The bacterial community composition of the ambient water and that associated with copepods were significantly different (Unifrac significance test, $\mathrm{p}<0.001$, Bonferroni corrected). The PCoA clearly separated ambientwater and copepod-associated bacterial communities (Fig. 4), with the first coordinate accounting for $42.6 \%$ and the second for $25.5 \%$ of the samples' variance. Furthermore, the bacterial communities of the ambient water clustered according to depth, and the copepodassociated bacteria according to the copepod order, but with a higher variability than the ambient-water bacterial communities (Fig. 4). In particular, the bacterial communities of 2 Cyclopoida samples were well

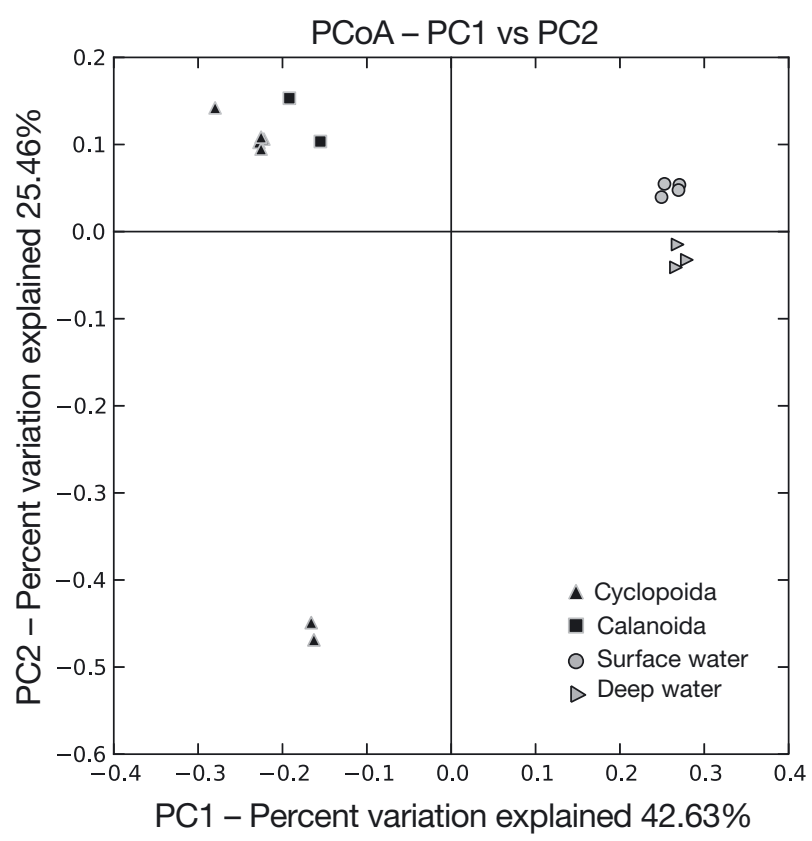

Fig. 4. Principal coordinates analysis (PCoA) of copepodassociated and ambient-water bacteria from individual samples. Bacterial communities from the same group of samples are represented by the same color

separated from the rest of the communities (Fig. 4) and had a lower bacterial diversity as compared to the other Cyclopoida samples (Table 1). These 2 Cyclopoida-associated bacterial communities were significantly different from the other Cyclopoida- and Calanoida-associated communities ( $\mathrm{p}<0.001$ Bonferroni corrected), and correspond to the communities associated with Oncaeidae and Lubbockiidae collected at Stn 4 as shown in Fig. 2.

The number of OTUs shared between the bacterial communities of the 2 depth layers and the copepod orders is indicated in Fig. 5. The 2 different copepod orders shared 191 (8.3\%) OTUs while the 2 depth layers $(100 \mathrm{~m}$ and $750 \mathrm{~m})$ shared only $84(3.7 \%)$ OTUs. Therefore, the number of shared OTUs was higher within the copepod-associated than within ambientwater bacterial communities. Only 33 (1.5\%) OTUs were ubiquitously present, i.e. in all 4 sample categories. These ubiquitously present OTUs consisted of the most abundant ambient-water OTUs such as SAR11, SAR324, Chloroflexi, Desulfobacterales, Rhodobacteraceae, and Synechococcophycideae. Furthermore, the bacterial communities from the ambient water and Cyclopoida-associated samples harbored a larger number of unique OTUs (510 [22.5\%] OTUs at $100 \mathrm{~m}$ depth, 540 [23.9\%] OTUs at $750 \mathrm{~m}$ depth, 676 [29.9\%] OTUs in Cyclopoida) than the community associated with Calanoida (241 OTUs, 10.6\%). 


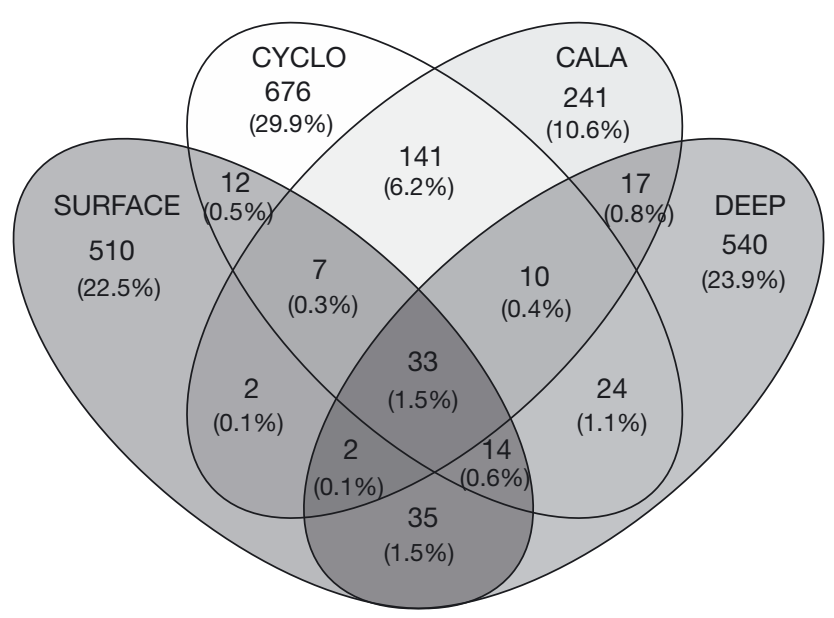

Fig. 5. Venn diagram showing the shared and unique bacterial operational taxonomic units (OTUs; $97 \%$ identity) and their relative contribution (in \%) in copepods (CALA: Calanoida; CYCLO: Cyclopoida) and ambient water (Surface and Deep)

\section{DISCUSSION}

In this study, we used a 454 high-throughput sequencing approach to characterize the bacterial community associated with 2 orders of copepods and to compare them to the bacterioplankton community of the ambient water collected at the same location. Generally, the bacterial community composition obtained in this study with 454 pyrosequencing differed from those reported in other marine and freshwater zooplankton studies using different techniques such as cloning and sequencing, agar plating, and CARDFISH (Sochard et al. 1979, Hansen \& Bech 1996, Peter \& Sommaruga 2008, Grossart et al. 2009, Tang et al. 2010, Freese \& Schink 2011). These differences are likely attributable to the different approaches used to investigate the bacterial community associated with the zooplankton. Early studies on zooplanktonassociated bacteria used agar-plating approaches and consequently underestimated bacterial diversity (Sochard et al. 1979, Hansen \& Bech 1996). However, the bacterial community associated with copepods obtained with the pyrosequencing technique was comparable to a study conducted on freshwater zooplankton-associated bacterial communities using denaturing gradient gel electrophoresis (DGGE) combined with sequencing (Grossart et al. 2009, Tang et al. 2010). In the latter study, the bacterial community associated with Thermocyclops oithonoides (a marine and brackish cyclopoid copepod) was dominated by Betaproteobacteria, Bacteroidetes, and Actinobacteria, followed by Alpha-, and
Gammaproteobacteria and Firmicutes (genus Bacillus) in partial agreement with our finding, considering the limited resolution of fingerprinting techniques such as DGGE.

The limited amount of data available and the different methods used to determine the zooplanktonassociated bacterial community composition preclude a thorough assessment of compositional differences in bacterial communities between zooplankton species or different oceanic provinces. However, the available data indicate considerable interspecific variability in the composition of the zooplankton-associated bacterial community (Tang et al. 2010). This microbial community is mainly associated with the exoskeleton and gut, which provide a favorable environment for bacterial attachment and growth (Nagasawa \& Nemoto 1988, Pruzzo et al. 1996, Carman \& Dobbs 1997).

\section{Diversity and taxonomic composition of copepod-associated bacteria}

Previous studies indicated that the bacterial community associated with the gut of crustacean zooplankton consists of 2 different bacterial communities: the resident bacteria persistently living in the gut and hence representing the stable component of the gut community, and the transient bacteria representing the variable gut community just passing through the digestive system of the host (Harris 1993, Tang et al. 2010). In our study, some bacterial phylotypes were consistently and abundantly found associated with the copepods and absent or only present in low abundances in the surrounding water (Fig. 3). However, some taxa of the copepod-associated bacteria varied considerably in abundance between the individual copepod samples, particularly in 2 out of the 9 copepod samples (Fig. 2, Table 2). These 2 Cyclopoida-associated bacterial communities deviated substantially from the community composition of the other 7 samples of copepod-associated bacteria and were characterized by a very low abundance of chloroplasts $(0.5 \%$ of total sequences; Fig. 2a). This may suggest that the gut was empty at the moment of the extraction of the sample. These pronounced differences between the rather similar bacterial community composition of the 2 Calanoida and 5 Cyclopoida samples, on the one hand, and the 2 Betaproteobacteria-dominated communities in the other 2 Cyclopoida samples, on the other hand, might reflect differences between the bacterial community composition with a filled gut (resident plus transient bacterial community) and after gut evacuation (resi- 
dent bacteria; Grossart et al. 2009). After gut evacuation, only the resident bacteria adapted to live and persist in the short gut of the copepods are detectable (Grossart et al. 2009, Tang et al. 2010). An alternative explanation for these pronounced differences in the bacterial community composition between the $2 \mathrm{Cy}$ clopoida samples and the other zooplankton samples might be due to differences in the food sources, physiological state, or environmental conditions to which the zooplankton were exposed prior to sampling.

Intriguingly, we did not obtain Vibrio spp. sequences in our copepod samples, in contrast to other studies that analyzed copepod-associated pathogens in costal and estuarine environments (Huq et al. 1983, Heidelberg et al. 2002, Vezzulli et al. 2010). Although Vibrio spp. play an important role in the mineralization of chitin (Huq et al. 1983, Bassler et al. 1991, Heidelberg et al. 2002) and account for a significant proportion of the zooplankton-associated microbial community (Huq et al. 1983, Heidelberg et al. 2002), their role in the open ocean zooplankton remains unknown.

\section{Comparison between the copepod-associated and the ambient-water bacterial communities}

Grossart et al. (2009) suggested that the diversity of bacteria associated with zooplankton is mainly dependent on host-symbiont interactions, food, and the ambient bacterial community to which the host is exposed. We compared the copepod-associated bacteria to the bacterioplankton to determine the linkage between the 2 bacterial communities. Despite the significant differences between the copepodassociated and the ambient-water bacterial communities (Figs. $2 \& 3$ ), the presence of shared OTUs (Fig. 5) between all the samples $(1.5 \%$ of the total OTUs) suggests a limited exchange of bacteria between the ambient water and the copepods.

The long tail of rare OTUs obtained for the ambient water in the rank-frequency distribution (Fig. S2) might provide a seed-bank of OTUs adapted to environmental conditions different from those prevailing in the ambient water (Pedrós-Alió 2006). However, we were not able to detect OTUs of the resident copepod-associated bacterial community in the ambient water, most likely because of the insufficient coverage of the ambient-water community (Fig. 1).

Taken together, our findings point toward a dynamic relationship between bacteria, zooplankton, and the environment where the dispersal of the copepodassociated transient bacterial community is mainly related to the ingestion and egestion of the food. The development of the resident copepod-associated bacterial community is likely governed by the specific microenvironmental conditions in copepods. The extent to which the transient, and particularly the resident, copepod-associated bacterial communities vary in their composition due to the quality of food sources and periodicity in feeding activity remains to be shown.

\section{CONCLUSION}

We found significant differences between bacterial communities associated with copepods and those of the ambient water. However, our data suggest a dynamic linkage between these 2 communities. This interaction most likely affects the copepod-associated bacterial activity and diversity. Moreover, the bacterial diversity associated with zooplankton greatly diverged in 2 out of 9 samples, with specific phylogenetic groups dominating in these 2 samples, suggesting that the food sources and feeding status of the zooplankton might influence the bacterial community composition associated with the guts of copepods.

Acknowledgements. We thank the captain and crew of the RV 'Pelagia' for their support and splendid atmosphere on board. E.S. was supported by the ESF EuroCores project MOCA financed via the Austria Science Fund (FWF, project number I 486-B09) and the FWF project MICRO-ACT (project number 23234-B11). Analytical work was supported by the FWF project Z194-B17 to G.J.H. and by the Marie Curie Fellowship (PIEF-GA-2011-299860) to D.D.C. We thank Jefferson Turner for his comments and the English editing of the manuscript.

\section{LITERATURE CITED}

Alldredge AL (2000) Interstitial dissolved organic carbon (DOC) concentrations within sinking marine aggregates and their potential contribution to carbon flux. Limnol Oceanogr 45:1245-1253

Alldredge AL, Cohen Y (1987) Can microscale chemical patches persist in the sea? Microelectrode study of marine snow, fecal pellets. Science 235:689-691

Altschul SF, Madden TL, Schaffer AA, Zhang J, Zhang Z, Miller W, Lipman DJ (1997) Gapped BLAST and PSIBLAST: a new generation of protein database search programs. Nucleic Acids Res 25:3389-3402

Azam F, Fenchel T, Field JG, Gray JS, Meyer-Reil LA, Thingstad F (1983) The ecological role of water-column microbes in the sea. Mar Ecol Prog Ser 10:257-263

Bassler BL, Yu C, Lee YC, Roseman S (1991) Chitin utilization by marine-bacteria - degradation and catabolism of chitin oligosaccharides by Vibrio furnissii. J Biol Chem 266:24276-24286 
Bell CR, Albright LJ (1982) Attached and free-floating bacteria in a diverse selection of water bodies. Appl Environ Microbiol 43:1227-1237

Bochdansky AB, Herndl GJ (1992) Ecology of amorphous aggregations (marine snow) in the Northern Adriatic Sea. V. Role of fecal pellets in marine snow. Mar Ecol Prog Ser 89:297-303

- Bochdansky AB, van Aken HM, Herndl GJ (2010) Role of macroscopic particles in deep-sea oxygen consumption. Proc Natl Acad Sci USA 107:8287-8291

Caporaso JG, Kuczynski J, Stombaugh J, Bittinger K and others (2010) QIIME allows analysis of high-throughput community sequencing data. Nat Methods 7:335-336

Carman KR, Dobbs FC (1997) Epibiotic microorganisms on copepods and other marine crustaceans. Microsc Res Tech 37:116-135

Caron DA (1987) Grazing of attached bacteria by heterotrophic microflagellates. Microb Ecol 13:203-218

> Deangelis MA, Lee C (1994) Methane production during zooplankton grazing on marine phytoplankton. Limnol Oceanogr 39:1298-1308

> Freese HM, Schink B (2011) Composition and stability of the microbial community inside the digestive tract of the aquatic crustacean Daphnia magna. Microb Ecol 62: 882-894

> Grossart HP, Tang KW (2010) www.aquaticmicrobial.net. Commun Integr Biol 3:491-494

> Grossart HP, Kiørboe T, Tang KW, Allgaier M, Yam EM, Ploug $H$ (2006) Interactions between marine snow and heterotrophic bacteria: aggregate formation and microbial dynamics. Aquat Microb Ecol 42:19-26

> Grossart HP, Dziallas C, Tang KW (2009) Bacterial diversity associated with freshwater zooplankton. Environ Microbiol Rep 1:50-55

Grossart HP, Dziallas C, Leunert F, Tang KW (2010) Bacteria dispersal by hitchhiking on zooplankton. Proc Natl Acad Sci USA 107:11959-11964

> Hansen B, Bech G (1996) Bacteria associated with a marine planktonic copepod in culture. 1. Bacterial genera in seawater, body surface, intestines and fecal pellets and succession during fecal pellet degradation. J Plankton Res 18:257-273

> Harris JM (1993) The presence, nature, and role of gut microflora in aquatic invertebrates - a synthesis. Microb Ecol 25:195-231

> Heidelberg JF, Heidelberg KB, Colwell RR (2002) Bacteria of the $\gamma$-subclass Proteobacteria associated with zooplankton in Chesapeake Bay. Appl Environ Microbiol 68:5498-5507

Huq A, Small EB, West PA, Huq MI, Rahman R, Colwell RR (1983) Ecological relationships between Vibrio cholerae and planktonic crustacean copepods. Appl Environ Microbiol 45:275-283

> Huson DH, Auch AF, Qi J, Schuster SC (2007) MEGAN analysis of metagenomic data. Genome Res 17:377-386

Karner M, Herndl GJ (1992) Extracellular enzymatic activity and secondary production in free-living and marinesnow-associated bacteria. Mar Biol 113:341-347

Kobari T, Ikeda T (2001) Ontogenetic vertical migration and life cycle of Neocalanus plumchrus (Crustacea: Copepoda) in the Oyashio region, with notes on regional variations in body sizes. J Plankton Res 23:287-302

Lozupone C, Knight R (2005) UniFrac: a new phylogenetic method for comparing microbial communities. Appl Environ Microbiol 71:8228-8235

Editorial responsibility: Fereidoun Rassoulzadegan, Villefranche-sur-Mer, France
Møller EF (2007) Production of dissolved organic carbon by sloppy feeding in the copepods Acartia tonsa, Centropages typicus, and Temora longicornis. Limnol Oceanogr 52:79-84

> Møller EF, Thor P, Nielsen TG (2003) Production of DOC by Calanus finmarchicus, C. glacialis and C. hyperboreus through sloppy feeding and leakage from fecal pellets. Mar Ecol Prog Ser 262:185-191

Muyzer G, Brinkhoff T, Nübel U, Santegoeds C, Schäfer H, Wawer C (1998) Denaturing gradient gel electrophoresis (DGGE) in microbial ecology. In: Akkermans ADL, van Elsas JD, de Bruijn FJ (eds) Molecular microbial ecology manual, Book 3.4.4. Kluwer Academic Publishers, Dordrecht, p 1-27

- Nagasawa S, Nemoto $\mathrm{T}$ (1988) Presence of bacteria in guts of marine crustaceans and on their fecal pellets. J Plankton Res 10:559-564

> Pedrós-Alió C (2006) Genomics and marine microbial ecology. Int Microbiol 9:191-197

> Peter H, Sommaruga R (2008) An evaluation of methods to study the gut bacterial community composition of freshwater zooplankton. J Plankton Res 30:997-1006

> Pruzzo C, Crippa A, Bertone S, Pane L, Carli A (1996) Attachment of Vibrio alginolyticus to chitin mediated by chitin-binding proteins. Microbiology 142:2181-2186

Riemann L, Grossart HP (2008) Elevated lytic phage production as a consequence of particle colonization by a marine Flavobacterium (Cellulophaga sp.). Microb Ecol 56: 505-512

Sayers EW, Barrett T, Benson DA, Bolton E and others (2012) Database resources of the National Center for Biotechnology Information. Nucleic Acids Res 40:D13-D25

Schloss PD (2009) A high-throughput DNA sequence aligner for microbial ecology studies. PLoS ONE 4:e8230

Simon M, Grossart HP, Schweitzer B, Ploug H (2002) Microbial ecology of organic aggregates in aquatic ecosystems. Aquat Microb Ecol 28:175-211

Sochard MR, Wilson DF, Austin B, Colwell RR (1979) Bacteria associated with the surface and gut of marine copepods. Appl Environ Microbiol 37:750-759

Steinberg DK, Carlson CA, Bates NR, Goldthwait SA, Madin LP, Michaels AF (2000) Zooplankton vertical migration and the active transport of dissolved organic and inorganic carbon in the Sargasso Sea. Deep-Sea Res I 47:137-158

> Tang KW (2005) Copepods as microbial hotspots in the ocean: effects of host feeding activities on attached bacteria. Aquat Microb Ecol 38:31-40

> Tang KW, Turk V, Grossart HP (2010) Linkage between crustacean zooplankton and aquatic bacteria. Aquat Microb Ecol 61:261-277

> Tang KW, Glud RN, Glud A, Rysgaard S, Nielsen TG (2011) Copepod guts as biogeochemical hotspots in the sea: evidence from microelectrode profiling of Calanus spp. Limnol Oceanogr 56:666-672

> Unanue M, Ayo B, Azua I, Barcina I, Iriberri J (1992) Temporal variability of attached and free-living bacteria in coastal waters. Microb Ecol 23:27-39

> Vezzulli L, Pruzzo C, Huq A, Colwell RR (2010) Environmental reservoirs of Vibrio cholerae and their role in cholera. Environ Microbiol Rep 2:27-33

> Weinbauer MG, Fritz I, Wenderoth DF, Hofle MG (2002) Simultaneous extraction from bacterioplankton of total RNA and DNA suitable for quantitative structure and function analyses. Appl Environ Microbiol 68:1082-1087

Submitted: October 29, 2013; Accepted: March 25, 2014

Proofs received from author(s): May 9, 2014 